\title{
YKL-40 protein expression in human tumor samples and human tumor cell line xenografts: implications for its use in tumor models
}

\author{
Lukas Clemens Böckelmann $^{1,2} \cdot$ Theresa Felix $^{1} \cdot$ Simona Calabrò $^{1} \cdot$ Udo Schumacher $^{1}$
}

Accepted: 30 July 2021 / Published online: 25 August 2021

(C) The Author(s) 2021, corrected publication 2022

\begin{abstract}
Background YKL-40, also known as non-enzymatic chitinase-3 like-protein-1 (CHI3L1), is a glycoprotein expressed and secreted mainly by inflammatory cells and tumor cells. Accordingly, several studies demonstrated elevated YKL-40 serum levels in cancer patients and found YKL-40 to be correlated with a poor prognosis and disease severity in some tumor entities. YKL-40 was suggested to be involved in angiogenesis and extracellular matrix remodeling. As yet, however, its precise biological function remains elusive.

Methods As YKL-40 protein expression has only been investigated in few malignancies, we employed immunohistochemical detection in a large multi-tumor tissue microarray consisting of 2,310 samples from 72 different tumor entities. In addition, YKL-40 protein expression was determined in primary mouse xenograft tumors derived from human cancer cell lines.

Results YKL-40 could be detected in almost all cancer entities and was differently expressed depending on tumor stage and subtype (e.g., thyroid cancer, colorectal cancer, gastric cancer and ovarian cancer). While YKL-40 was absent in in vitro grown human cancer cell lines, YKL-40 expression was upregulated in xenograft tumor tissues in vivo.

Conclusions These data provide new insights into YKL-40 expression at the protein level in various tumor entities and its regulation in tumor models. Our data suggest that upregulation of YKL-40 expression is a common feature in vivo and is finely regulated by tumor cell-microenvironment interactions.
\end{abstract}

Keywords Cancer $\cdot$ CHI3L1 $\cdot$ Immunohistochemistry $\cdot$ Tissue array $\cdot$ Tumorigenesis $\cdot$ Xenograft $\cdot$ YKL-40

\section{Introduction}

YKL-40, also known as chitinase-3-like protein 1 (CHI3L1) is, as its name implicates, a chitinase-like glycoprotein, but is devoid of chitinase activity caused by mutations present in its active site $[1,2]$. It is secreted by a variety of cells including cancer cells, inflammatory cells such as (tumor-associated) macrophages and neutrophils, and by chondrocytes, synovial cells and smooth muscle cells [3-8]. Accordingly, elevated

Lukas Clemens Böckelmann

1.boeckelmann@uke.de

1 Institute of Anatomy and Experimental Morphology, Center for Experimental Medicine, University Cancer Center Hamburg, University Medical Center Hamburg-Eppendorf, Hamburg, Germany

2 Department of Oncology, Hematology and Bone Marrow Transplantation With Section Pneumology, University Cancer Center Hamburg, University Medical Center Hamburg-Eppendorf, Hamburg, Germany serum levels of YKL-40 have been found in various inflammatory and malignant diseases [9-11]. Some studies have demonstrated a positive correlation of elevated serum levels of YKL-40 and a poor prognosis in solid tumors while others presented negative results [12]. In case a correlation between YKL-40 secretion and malignant progression exists, it has been suggested that YKL-40 exerts its function mainly by stimulation of angiogenesis and regulation of extracellular matrix signaling [13-18]. A key component of this function is thought to be the ability of YKL-40 to bind to heparin and extracellular and cell surface heparan sulfate [19]. Moreover, YKL-40 is known to play a potential role in promoting tumor cell proliferation and survival and to exhibit own growth factor activity [13, 20, 21]. Studies investigating YKL-40 as a therapeutic target, however, yielded opposing results. In one study, the application of a neutralizing anti-YKL-40 antibody reduced tumor growth in a human glioblastoma (U87) xenograft model [22]. In another human melanoma xenograft (LOX) model targeting YKL-40 led to increased tumor growth within hours after injection [23]. 
Given the multiple and diverse functions attributed to YKL-40 and the reported opposing functions it can execute in malignant progression, its expression may differ depending on tumor entity and tumor subtype. Comprehensive protein expression data in tumor tissues, however, are lacking. Therefore, we set out to assess YKL-40 protein expression immunohistochemically in a large multi-tumor tissue microarray (TMA). In addition, we analyzed YKL-40 expression in widely used tumor cell lines taken directly from 2D cultures and from xenograft tumor tissues of these cell lines.

\section{Materials and methods}

\subsection{Xenograft tumors of human cancer cell lines}

Xenografted primary human tumors grown in immunodeficient scid mice were retrieved from the files of the Institute of Anatomy and Experimental Morphology from previous experiments. Small cell lung cancer: H69AR (RRID:CVCL_3513)*, NCI-H69 (RRID:CVCL_1579)*, NCI-H82 (RRID:CVCL_1591)*, and SW2 (RRID:CVCL_R777)* [24]; colon cancer: HT-29 (RRID:CVCL_0320)*, SW480 (RRID:CVCL_0546)*, $\mathrm{CaCo} 2$ (RRID:CVCL_0025)*, and HCT-116 (RRID:CVCL_0291)* [25, 26]; breast cancer: DU4475 (RRID:CVCL_1183)*, MCF-7 (RRID:CVCL_0031)*, MDA-MB-231 (RRID:CVCL_0062)*, and T-47D (RRID:CVCL_0553)* [25, 27, 28]; melanoma: FEMX-1 (RRID:CVCL_A011)*, LOX-IMVI (RRID:CVCL_1381)*, MDA-MB-435 (RRID:CVCL_0417)*, MeWo (RRID:CVCL_0445)*, and MV3 (RRID:CVCL_W280* [27, 29]; neuroblastoma: LA-N-1 (RRID:CVCL_1827)*, LA-N-5 (RRID:CVCL_0389), SK-N-SH (RRID:CVCL_D044), IMR32 (RRID:CVCL_0346), KELLY (RRID:CVCL_2092), and LS (RRID:CVCL_2105) [30]; osteosarcoma: HOS (RRID:CVCL_0312)* and U2OS (RRID:CVCL_0042); pancreatic cancer: PaCa5072 (RRID:CVCL_C887)*, PaCa5061 (RRID:CVCL_C886)*, BxPC-3 (RRID:CVCL_0186)*, and PANC-1 (RRID:CVCL_0480)* [31]; prostate cancer: DU145 (RRID:CVCL_0105)*, LNCaP (RRID:CVCL_0395)*, PC-3 (RRID:CVCL_0035)*, and C5 [32, 33]; ovarian cancer: OVCAR3 (RRID:CVCL_0465)* and SKOV3 (RRID:CVCL_0532)* [26]; head and neck squamous cancer: UT-SCC-2 (RRID:CVCL_7820)*, UT-SCC-16A (RRID:CVCL_7812)*, UT-SCC-24A (RRID:CVCL_7826)*, UT-SCC-24B (RRID:CVCL_7827)*, UT-SCC-60A (RRID:CVCL_A089)*, and Carey24 [34]. Cell lines marked with an asterisk have been authenticated by the DSMZ-German Collection of Microorganisms and Cell Cultures GmbH, Braunschweig, Germany using short tandem repeat (STR) profiling.

\subsection{Multi-tumor tissue microarray (TMA)}

For the production of TMAs, tissue cylinders with a diameter of $0.6 \mathrm{~mm}$ were punched from representative tumor or normal areas of each tissue block and transferred to recipient paraffin blocks. All tumor samples were obtained from the archives of the Institute of Pathology of the University Medical Center Hamburg Eppendorf. The use of archived diagnostic left-over tissues for the manufacturing of TMAs and their analysis for research purposes has been approved by local laws (HmbKHG, §12,1) and by the local ethics committee (Ethics commission Hamburg, WF-049/09). All work was carried out in compliance with the Helsinki Declaration. Freshly cut TMA sections were immunostained on one day and in one experiment (see below).

\subsection{Fixation, embedding and sectioning of cancer cells and xenograft tumors}

Preparation of cancer cells as formalin-fixed paraffin-embedded (FFPE) samples was carried out as previously described [35]. Briefly, cancer cells were collected from culture flasks, fixed in formalin and next embedded into agar pellets. Agar pellets and formalin-fixed xenograft tumors were then subjected to standardized tissue infiltration using a Leica TP1020 tissue processor (Leica Biosystems, Nussloch, Germany). Subsequent paraffin embedding was performed using a Leica EG1160 Paraffin Embedding Center (Leica Biosystems, Nussloch, Germany). FFPE samples were sectioned with a thickness of $4 \mu \mathrm{m}$, mounted on HistoBond® glass slides (Paul Marienfeld, Lauda-Königshofen, Germany) and allowed to air-dry, followed by drying in an incubator at $37{ }^{\circ} \mathrm{C}$ overnight.

\subsection{Immunohistochemistry (IHC)}

FFPE sections were de-paraffinized in two changes of xylene replacement (5 min each) and rehydrated in a series of graded ethanol (100, 96, 70 and 50\% for 5 min each). Next, sections were rinsed for $5 \mathrm{~min}$ each with Tris-buffered saline/0.1\% Tween 20 (TBS-T) and TBS (pH 7.6). The subsequent incubation steps were carried out in a moist chamber. Sections were blocked with goat serum (\#X0907, Dako, Carpinteria, CA, USA; diluted 1:10) for $30 \mathrm{~min}$ at room temperature (RT). Directly afterwards, sections were incubated with an antiYKL-40 primary monoclonal mouse antibody (MAb 201.F9, $2.1 \mathrm{mg} / \mathrm{ml}$, IgG2b, epitope GAWRGTTGHHS, aa 210-220) diluted 1:100 in antibody diluent (\#S0809, Dako, Carpinteria, CA, USA) for $60 \mathrm{~min}$ at RT. For isotype control, mouse IgG2b antibody (\#16-4732-85, eBioscience, San Diego, CA, USA; diluted 1:50) was used. Staining specificity was validated by preincubation of antibody MAb 201.F9 with recombinant 
human YKL-40 protein (\#2599-CH, R\&D Systems, Minneapolis, MN, USA) for $1 \mathrm{~h}$ at RT to block YKL-40 binding sites and reveal possible nonspecific staining to the sections (Supplementary Fig. S2). After incubation, slides were rinsed twice with TBS-T as well as with TBS for 5 min each. Subsequently, slides were incubated with secondary biotin-conjugated goat anti-mouse antibody (\#E0433, Dako, Carpinteria, CA, USA) at a dilution of 1:200 in TBS for $30 \mathrm{~min}$ at RT, followed by rinsing twice with TBS-T and once with TBS for 5 min each. Next, sections were treated with Vectastain ${ }^{\circledR}$ ABC-AP Kit (\#AK5000, Linaris, Drossenheim, Germany) according to the manufacturer's recommendations for $30 \mathrm{~min}$ at RT and again washed in TBS-T and TBS as described above. Finally, alkaline phosphatase enzyme activity was visualized by incubating the sections with Permanent Red solution (\#ZUC001125, Zytomed Systems GmbH, Berlin, Germany) for $20 \mathrm{~min}$ and counterstained with hematoxylin for $4 \mathrm{~s}$, with intermediate washes under running tap water ( $3 \mathrm{~min}$ ) and in aqua dest ( $2 \mathrm{~min}$ ). Slides were dehydrated in a series of graded ethanol (70\% for $15 \mathrm{~s}, 96$ and $100 \%$ for $5 \mathrm{~min}$ each) and three changes of xylene replacement (5 min each) and, finally, covered with Eukitt® Mounting Medium (\#03989, Sigma-Aldrich, Taufkirchen, Germany) and coverslips.

\subsection{Microscopy and image analysis}

IHC processed sections were first evaluated using a ZEISS Axiophot 2 microscope (Carl Zeiss, Jena, Germany). Digital images were obtained using a ZEISS Axio Scan Z1 slide scanner equipped with a ZEISS EC Plan-Neofluar 20x/0,50 Pol M27 objective (Carl Zeiss, Jena, Germany) and a Hitachi HV-F20SCL camera with $1600 \times 1200$ pixels (Hitachi Kokusai Electric America Ltd., NY, USA). For image acquisition, ZEISS ZEN 2.3 software was used (Carl Zeiss, Jena, Germany). Images were further processed using netScope Viewer software (Net-Base Software, Freiburg, Germany).

YKL-40 staining was observed in the cytoplasm and as fine granular staining in the extracellular matrix. Staining intensity was assessed on a five-step scale (negative, weak, intermediate-low, intermediate-high, high). Further analysis included trichotomization of staining intensities (negative; weak and intermediate-low = 'low'; intermediate-high and high $=$ 'high').

\section{Results}

\subsection{YKL-40 protein expression in primary human tumor samples}

In our TMA analysis 2,310 of 3,079 tumor samples were interpretable. Non-informative cases $(n=769 ; 25 \%)$ were due to lack of tissue samples or absence of unequivocal cancer tissues in the respective TMA spots. In the total cohort, negative ('0') YKL-40 expression was found in $15.9 \%$ of all cancers, low (' 1 ') in $20 \%$, intermediate-low ('2') in $33.6 \%$, intermediate-high (' 3 ') in $22.2 \%$, and high expression ('4') in $8.4 \%$ of the cancers (Table 1 and Fig. 2). YKL-40 protein expression was observed as a diffuse, often granular, cytoplasmatic staining with varying intensity. Cell membranes were consistently negative. In most tumors the extracellular matrix showed varying granular staining, suggesting that the cancer cells had released YKL-40. Tumor-infiltrating leukocytes residing in the adjacent tumor stroma frequently stained positive (Fig. 6d-f). The percentage of tumor samples with positive stroma cell staining and the proportion of tumor samples with staining intensity in stroma cells surpassing that in tumor cells are reported in Table 1 as well. Representative IHC images of negative, intermediate-low, intermediatehigh, and strong YKL-40 protein expression are shown in Fig. 1. Anti YKL-40 monoclonal antibody Mab 201. F9 was tested to be specific for human YKL-40. Crossreactivity with murine YKL-40 was excluded (Supplementary Fig. S1).

\subsection{YKL-40 is differently expressed in tumor subtypes}

Previously, YKL-40 was found to be elevated in sera of various tumor patients including those carrying solid tumors, leukemias and lymphomas [36]. In our study, a striking difference in YKL-40 tissue protein expression was observed when comparing solid tumors with lymphomas. About 50\% of all Hodgkin and Non-Hodgkin lymphomas did not show any YKL-40 expression using IHC (Fig. 2). This observation suggests that in lymphomas a substantial proportion of serum YKL-40 may be derived from stroma and immune cells due to the tumor's immunologic reaction, rather than from the tumors cells themselves.

In solid tumors, on the other hand, tumor samples stained positive more frequently and YKL-40 was differently expressed depending on tumor subtype (Fig. 3). For further analysis, we trichotomized our results into a YKL-40 negative group, a YKL-40 low (low and intermediate-low) group and a YKL-40 high (intermediate-high and high) group to more clearly highlight those tumors and subtypes with differentially regulated YKL-40 expression. Accordingly, in the total cohort, negative YKL-40 expression was found in $15.9 \%$ of all cancers, while low YKL-40 expression was found in $53.6 \%$, and high expression in $30.5 \%$ of all cancers. In the past, elevated serum YKL-40 levels have been proposed as prognostic biomarkers in some cancer entities. This association can be recapitulated for some entities analyzed 
Table 1 Immunohistochemical detection of YKL-40 protein expression in a multi-tumor tissue microarray Staining intensity was assessed on a scale from ' 0 ' $=$ negative over ' 1 ' $=$ weak to ' 4 ' $=$ high expression

\begin{tabular}{|c|c|c|c|c|c|c|c|c|c|c|}
\hline \multirow[b]{2}{*}{ Organ system } & \multirow[b]{2}{*}{ Tissue } & \multirow[b]{2}{*}{ Specific tumor entity } & \multirow[b]{2}{*}{$\mathrm{n}$} & \multicolumn{5}{|c|}{ YKL-40 Staining Intensity \% } & \multicolumn{2}{|c|}{ Matrix Cells \% } \\
\hline & & & & 0 & 1 & 2 & 3 & 4 & Pos & $>$ Tumor \\
\hline \multirow[t]{4}{*}{ Skin } & & Basalioma & 41 & 4.9 & 36.6 & 46.3 & 12.2 & 0.0 & 76.2 & 48.8 \\
\hline & & Benign Naevus & 26 & 0.0 & 11.5 & 26.9 & 42.3 & 19.2 & 81.5 & 7.7 \\
\hline & & Squamous cell carcinoma & 43 & 7.0 & 14.0 & 39.5 & 23.3 & 16.3 & 55.6 & 14.0 \\
\hline & & Melanoma & 42 & 7.1 & 16.7 & 21.4 & 35.7 & 19.0 & 78.0 & 26.8 \\
\hline \multirow{10}{*}{$\begin{array}{l}\text { Head, Chest, and } \\
\text { Respiratory Tract }\end{array}$} & Larynx & Squamous cell carcinoma & 41 & 22.0 & 19.5 & 31.7 & 24.4 & 2.4 & 34.9 & 24.4 \\
\hline & Oral cavity & Squamous cell carcinoma & 50 & 2.0 & 10.0 & 32.0 & 48.0 & 8.0 & 71.4 & 10.2 \\
\hline & Lung & Squamous cell carcinoma & 33 & 9.1 & 15.2 & 24.2 & 45.5 & 6.1 & 56.3 & 16.7 \\
\hline & & Bronchial carcinoma, large cell & 22 & 9.1 & 18.2 & 31.8 & 18.2 & 22.7 & 72.7 & 28.6 \\
\hline & & Adenocarcinoma & 32 & 0.0 & 9.4 & 31.3 & 40.6 & 18.8 & 90.6 & 22.6 \\
\hline & & Bronchoalveolar carcinoma & 6 & 0.0 & 33.3 & 50.0 & 16.7 & 0.0 & 16.7 & 0.0 \\
\hline & & Small-cell carcinoma & 19 & 0.0 & 5.3 & 52.6 & 26.3 & 15.8 & 50.0 & 100.0 \\
\hline & Salivary glands & Parotis, pleomorphic adenoma & 48 & 58.3 & 20.8 & 18.8 & 2.1 & 0.0 & 2.1 & 60.4 \\
\hline & & Parotis, Warthin tumor & 44 & 2.3 & 22.7 & 25.0 & 43.2 & 6.8 & 0.0 & 2.3 \\
\hline & & Basal cell adenoma & 14 & 7.1 & 28.6 & 35.7 & 28.6 & 0.0 & 21.4 & 7.1 \\
\hline \multirow[t]{18}{*}{ Gynecologic } & Vagina & Squamous cell carcinoma & 24 & 29.2 & 20.8 & 25.0 & 16.7 & 8.3 & 45.8 & 37.5 \\
\hline & Vulva & Squamous cell carcinoma & 33 & 0.0 & 6.1 & 30.3 & 39.4 & 24.2 & 60.0 & 12.1 \\
\hline & Cervix & Squamous cell carcinoma & 37 & 27.0 & 27.0 & 18.9 & 16.2 & 10.8 & 35.1 & 37.8 \\
\hline & & Adenocarcinoma & 44 & 2.3 & 11.4 & 40.9 & 34.1 & 11.4 & 55.6 & 6.8 \\
\hline & Endometrium & Carcinoma, endometroid & 47 & 55.3 & 27.7 & 17.0 & 0.0 & 0.0 & 4.3 & 59.6 \\
\hline & & Carcinoma, serous & 36 & 19.4 & 27.8 & 36.1 & 13.9 & 2.8 & 13.9 & 22.2 \\
\hline & Uterus & Stroma sarcoma & 12 & 8.3 & 8.3 & 50.0 & 33.3 & 0.0 & 50.0 & 16.7 \\
\hline & & Carcinosarcoma & 46 & 4.3 & 32.6 & 39.1 & 21.7 & 2.2 & 45.7 & 13.0 \\
\hline & Ovaries & Carcinoma, endometroid & 25 & 4.0 & 28.0 & 20.0 & 32.0 & 16.0 & 67.9 & 16.0 \\
\hline & & Carcinoma, serous & 39 & 5.1 & 15.4 & 46.2 & 23.1 & 10.3 & 76.2 & 26.3 \\
\hline & & Carcinoma, mucinous & 23 & 43.5 & 17.4 & 26.1 & 8.7 & 4.3 & 50.0 & 56.5 \\
\hline & & Brenner tumor & 5 & 80.0 & 0.0 & 20.0 & 0.0 & 0.0 & 66.7 & 80.0 \\
\hline & Breast & Carcinoma, ductal (NST) & 30 & 56.7 & 20.0 & 13.3 & 10.0 & 0.0 & 10.0 & 56.7 \\
\hline & & Carcinoma, lobular & 28 & 7.1 & 25.0 & 46.4 & 21.4 & 0.0 & 63.3 & 25.9 \\
\hline & & Carcinoma, medullary & 11 & 0.0 & 0.0 & 63.6 & 36.4 & 0.0 & 45.5 & 0.0 \\
\hline & & Carcinoma, tubular & 10 & 0.0 & 20.0 & 20.0 & 40.0 & 20.0 & 83.3 & 20.0 \\
\hline & & Carcinoma, mucinous & 14 & 7.1 & 21.4 & 14.3 & 28.6 & 28.6 & 35.7 & 21.4 \\
\hline & & Carcinoma, phyllodes & 44 & 18.2 & 43.2 & 27.3 & 11.4 & 0.0 & 47.8 & 50.0 \\
\hline \multirow[t]{15}{*}{ Gastrointestinal } & Large intestine & Adenoma, low grade & 17 & 29.4 & 23.5 & 29.4 & 11.8 & 5.9 & 17.6 & 29.4 \\
\hline & & Adenoma, high grade & 19 & 21.1 & 21.1 & 26.3 & 21.1 & 10.5 & 55.0 & 31.6 \\
\hline & & Adenocarcinoma & 32 & 3.1 & 15.6 & 34.4 & 43.8 & 3.1 & 56.3 & 12.5 \\
\hline & Small intestine & Adenocarcinoma & 6 & 0.0 & 0.0 & 83.3 & 16.7 & 0.0 & 71.4 & 33.3 \\
\hline & Stomach & Carcinoma, diffuse type & 29 & 65.5 & 27.6 & 6.9 & 0.0 & 0.0 & 37.5 & 86.2 \\
\hline & & Carcinoma, intestinal type & 30 & 3.3 & 16.7 & 46.7 & 26.7 & 6.7 & 74.2 & 20.7 \\
\hline & Esophagus & Adenocarcinoma & 31 & 29.0 & 32.3 & 22.6 & 12.9 & 3.2 & 34.4 & 35.5 \\
\hline & & Squamous cell carcinoma & 26 & 7.7 & 15.4 & 30.8 & 26.9 & 19.2 & 59.3 & 23.1 \\
\hline & Anal canal & Squamous cell carcinoma & 18 & 27.8 & 11.1 & 33.3 & 27.8 & 0.0 & 42.1 & 27.8 \\
\hline & Liver & Cholangiocellular carcinoma & 27 & 11.1 & 22.2 & 18.5 & 18.5 & 29.6 & 71.4 & 22.2 \\
\hline & & Hepatocellular carcinoma & 39 & 2.6 & 7.7 & 38.5 & 41.0 & 10.3 & 39.4 & 6.1 \\
\hline & Pancreas & Adenocarcinoma, ductal & 36 & 36.1 & 33.3 & 25.0 & 5.6 & 0.0 & 25.6 & 50.0 \\
\hline & & Adenocarcinoma, papillary & 18 & 33.3 & 50.0 & 11.1 & 5.6 & 0.0 & 16.7 & 44.4 \\
\hline & & Neuroendocrine Tumor & 27 & 7.4 & 18.5 & 40.7 & 18.5 & 14.8 & 57.1 & 14.8 \\
\hline & & Gastrointestinal Stroma tumor & 33 & 6.1 & 12.1 & 42.4 & 36.4 & 3.0 & 73.0 & 25.0 \\
\hline
\end{tabular}


Table 1 (continued)

\begin{tabular}{|c|c|c|c|c|c|c|c|c|c|c|}
\hline \multirow[b]{2}{*}{ Organ system } & \multirow[b]{2}{*}{ Tissue } & \multirow[b]{2}{*}{ Specific tumor entity } & \multirow[b]{2}{*}{$\mathrm{n}$} & \multicolumn{5}{|c|}{ YKL-40 Staining Intensity $\%$} & \multicolumn{2}{|c|}{ Matrix Cells \% } \\
\hline & & & & 0 & 1 & 2 & 3 & 4 & Pos & $>$ Tumor \\
\hline \multirow[t]{11}{*}{ Urogenital } & \multirow[t]{2}{*}{ Urothelial } & Carcinoma, pTa & 35 & 0.0 & 8.6 & 20.0 & 42.9 & 28.6 & 80.6 & 3.4 \\
\hline & & Carcinoma, pT2-4 & 43 & 0.0 & 9.3 & 25.6 & 44.2 & 20.9 & 97.6 & 23.8 \\
\hline & \multirow[t]{4}{*}{ Kidney } & Carcinoma, clear cell & 44 & 4.5 & 18.2 & 43.2 & 31.8 & 2.3 & 54.5 & 11.6 \\
\hline & & Carcinoma, papillary & 34 & 0.0 & 38.2 & 29.4 & 29.4 & 2.9 & 47.2 & 12.1 \\
\hline & & Carcinoma, chromophobe & 43 & 18.6 & 16.3 & 23.3 & 32.6 & 9.3 & 16.3 & 20.9 \\
\hline & & Oncocytoma & 41 & 2.4 & 0.0 & 9.8 & 19.5 & 68.3 & 56.1 & 2.4 \\
\hline & Prostate & Adenocarcinoma & 46 & 32.6 & 17.4 & 30.4 & 10.9 & 8.7 & 60.9 & 52.2 \\
\hline & \multirow[t]{4}{*}{ Germ cell tumor } & Seminoma & 48 & 2.1 & 16.7 & 68.8 & 12.5 & 0.0 & 68.1 & 23.4 \\
\hline & & Carcinoma, embryonal & 43 & 4.7 & 18.6 & 58.1 & 18.6 & 0.0 & 55.3 & 26.3 \\
\hline & & Yolk sac tumor & 41 & 4.9 & 19.5 & 41.5 & 22.0 & 12.2 & 57.9 & 18.9 \\
\hline & & Teratoma & 29 & 3.4 & 10.3 & 41.4 & 27.6 & 17.2 & 77.4 & 39.3 \\
\hline \multirow[t]{9}{*}{ Endocrine } & \multirow[t]{5}{*}{ Thyroid } & Adenoma & 42 & 11.9 & 40.5 & 31.0 & 11.9 & 4.8 & 45.2 & 23.8 \\
\hline & & Papillary carcinoma & 45 & 37.8 & 20.0 & 22.2 & 17.8 & 2.2 & 28.3 & 37.8 \\
\hline & & Follicular carcinoma & 45 & 4.4 & 26.7 & 42.2 & 17.8 & 8.9 & 47.8 & 11.1 \\
\hline & & Medullary carcinoma & 45 & 40.0 & 17.8 & 35.6 & 6.7 & 0.0 & 28.3 & 46.7 \\
\hline & & Anaplastic carcinoma & 24 & 8.3 & 20.8 & 33.3 & 25.0 & 12.5 & 37.5 & 20.8 \\
\hline & \multirow[t]{4}{*}{ Adrenal gland } & Adenoma & 43 & 2.3 & 9.3 & 62.8 & 25.6 & 0.0 & 7.0 & 4.7 \\
\hline & & Carcinoma & 13 & 7.7 & 23.1 & 30.8 & 23.1 & 15.4 & 15.4 & 8.3 \\
\hline & & Pheochromocytoma & 26 & 19.2 & 23.1 & 42.3 & 15.4 & 0.0 & 20.0 & 20.8 \\
\hline & & Neuroendocrine tumor & 22 & 18.2 & 18.2 & 54.5 & 4.5 & 4.5 & 45.8 & 36.4 \\
\hline \multirow[t]{3}{*}{ Hematologic } & & Hodgkin-Lymphoma & 37 & 62.2 & 24.3 & 10.8 & 2.7 & 0.0 & 45.9 & 75.7 \\
\hline & & Non-Hodgkin-Lymphoma & 42 & 54.8 & 26.2 & 14.3 & 4.8 & 0.0 & 47.6 & 57.1 \\
\hline & & Thymoma & 26 & 7.7 & 53.8 & 34.6 & 3.8 & 0.0 & 30.8 & 30.8 \\
\hline \multirow[t]{2}{*}{ Soft tissue } & & Leiomyoma & 48 & 8,3 & 29.2 & 45.8 & 14.6 & 2.1 & 0.0 & 8.3 \\
\hline & & Leiomyosarcoma & 48 & 8,3 & 10.4 & 56.3 & 22.9 & 2.1 & 35.4 & 12.5 \\
\hline
\end{tabular}

in our TMA, while for others prognostic associations are much less suggestive. In particular, we found that in thyroid cancer, the total proportion of YKL-40-positive tumors was relatively lower in the prognostically favorable papillary and medullary carcinomas $(62.2 \%$ and $60 \%$, respectively, Fig. 3a). Contrary, in prognostically less favorable follicular carcinomas, a considerably higher percentage of YKL40-positive tumors (95.6\%) was observed. Looking at the fraction of only YKL-40 strongly expressing tumors, it was found to be highest in undifferentiated anaplastic carcinomas (37\%) having a median survival of only a few months [37]. Similar, in colorectal cancer, positive YKL-40 tissue expression increased from low-grade over high-grade to adenocarcinoma (samples positive in 70.6, 78.9, and 96.9\%, respectively; Fig. 3b).

In other cancer entities, YKL-40 expression was found to be associated with certain tumor subtypes. In gastric cancer, YKL-40 expression was highly associated with the intestinal type (96.7\% positive), while $65.5 \%$ of tumors of the diffuse type were negative for YKL-40 expression (Fig. 3c). In serous and endometrioid differentiated ovarian cancer, YKL40 expression was present in 95 and $96 \%$ of the tumors, respectively. On the contrary, ovarian cancer samples of the mucinous type stained positive in only $56.5 \%$ of the cases, whereas benign Brenner tumors were positive in $20 \%$ of the cases (Fig. 3d).

When comparing adenocarcinomas with squamous cell carcinomas, no general distinguishing pattern of YKL-40 expression was observed between these two entities (Fig. 4). While in esophageal cancer, for example, YKL-40 expression was found to be linked to the squamous cell cancer subtype (high expression in $46.1 \%$ of samples versus $16.1 \%$ in adenocarcinomas, Fig. 3e). In cervical cancer specimens, however, YKL-40 was found to be linked to the adenocarcinoma subtype (high YKL-40 expression in $45.5 \%$ of samples versus $27 \%$ in squamous cell carcinomas, Fig. 3f). 
a
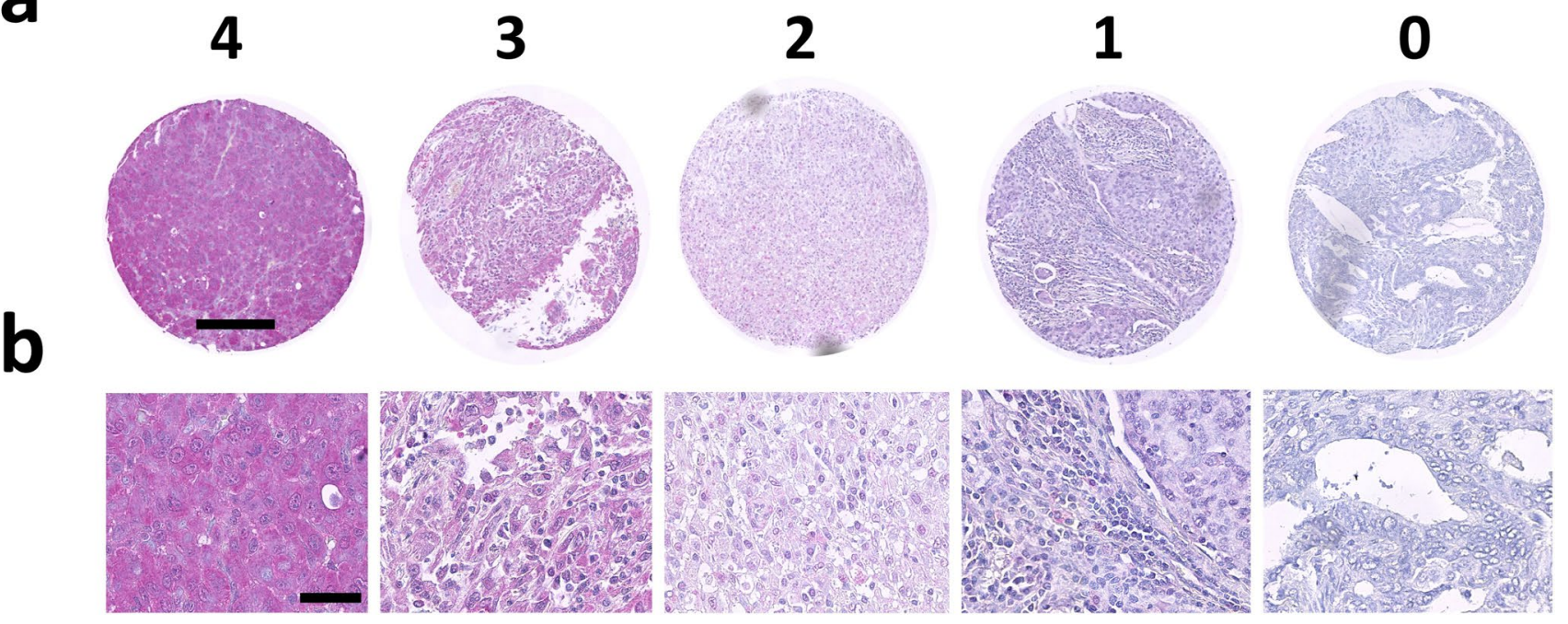

Fig. 1 Representative images of YKL-40 immunostaining results on multi-tumor tissue microarray (TMA). Cancer cells were identified morphologically, and the staining intensities were assigned to four categories: $4=$ high, $3=$ intermediate-high, $2=$ intermediate-low, $1=$ low, and $0=$ no staining. a Low magnification of whole tissue sample. Scale bar $=200 \mu \mathrm{m}$. b High magnification. Scale bar $=50 \mu \mathrm{m}$

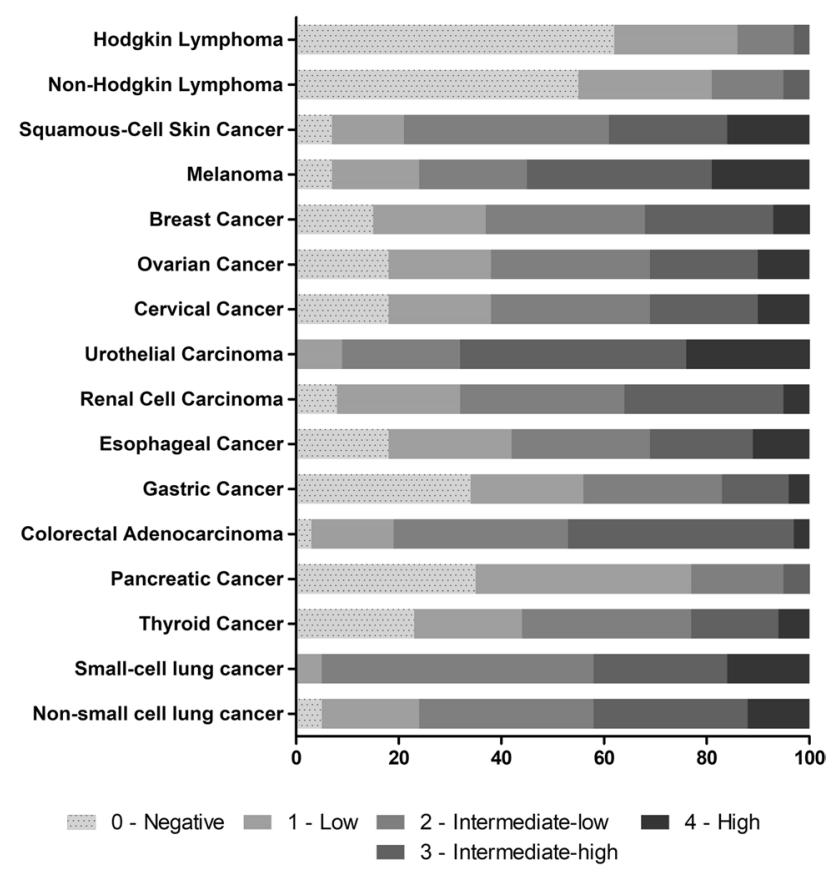

Fig. 2 Overview of YKL-40 protein expression in selected entities on multi-tumor TMA. Where applicable, subtypes were grouped and analyzed as one (see also Table 1)

\subsection{YKL-40 protein expression in xenograft tumors of human cancer cell lines}

Tumor models, especially cancer cell-derived mouse xenografts, are increasingly used in cancer research. However, protein expression levels may differ significantly from clinical patient tumor samples to those grown in cell culture or as xenograft primary tumors in mice. Therefore, we assessed YKL-40 protein expression in human cancer cell lines directly taken from 2D-culture and paired mouse xenograft tumors. Cell pellets were embedded in agar and routinely processed as FFPE blocks, so that from a methodological point of view they were treated in the same way as primary biopsy specimens. We found that YKL-40 expression was immunohistochemically undetectable in all cancer cells grown in vitro except in SW480, $\mathrm{CaCo} 2$ and OVCAR3 cells (data not shown). Interestingly, YKL-40 expression became frequently positive under in vivo conditions in mouse xenograft tumors, especially in melanoma, pancreatic and colorectal cancer models (Table 2, Fig. 5). Moreover, our data suggest that human YKL-40 was released from tumor cells into murine extracellular matrix components (Fig. 6a-c).

\subsection{YKL-40 expression analysis in publicly available datasets}

First, we checked the Broad Institute Cancer Cell Line Encyclopedia (CCLE) online tool for YKL-40 mRNA expression $[38,39]$. We found that in only in $19 \%$ of 1,019 cell lines with expression values for YKL-40, expression Z-scores were confidently above zero. Furthermore, we accessed publicly available GEO dataset GSE48433 comprising mRNA expression profiles of 49 human cancer cell lines and xenograft tumor fragments at passages 1, 4 and 10 from the Developmental Therapeutics Program of the National Cancer Institute (NCI DTP) [40]. In 33 out of 


\section{a Thyroid Cancer}

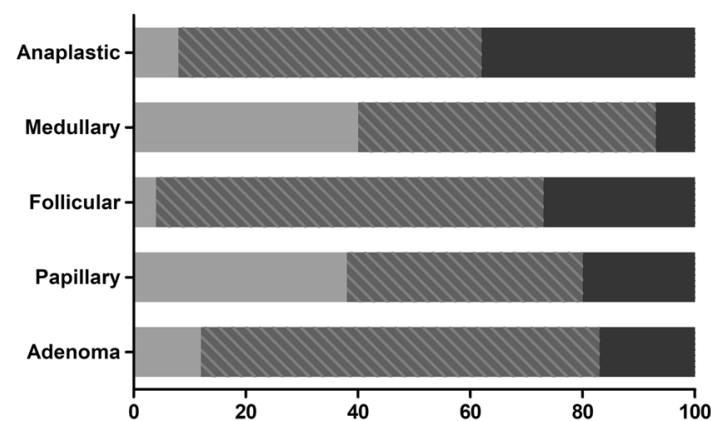

b Colorectal cancer

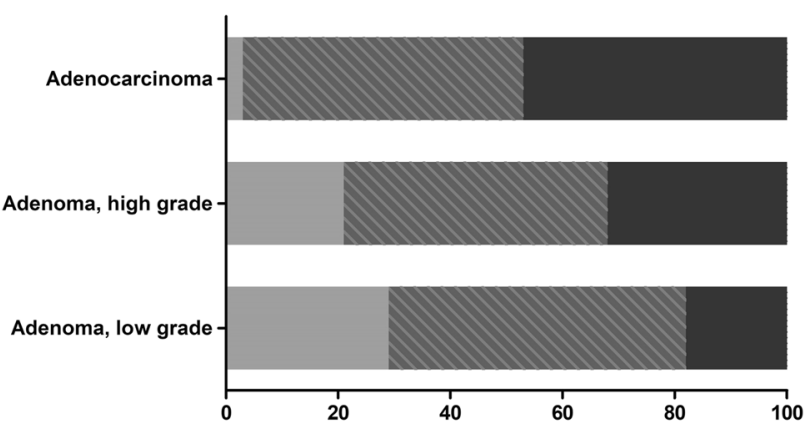

C Gastric cancer

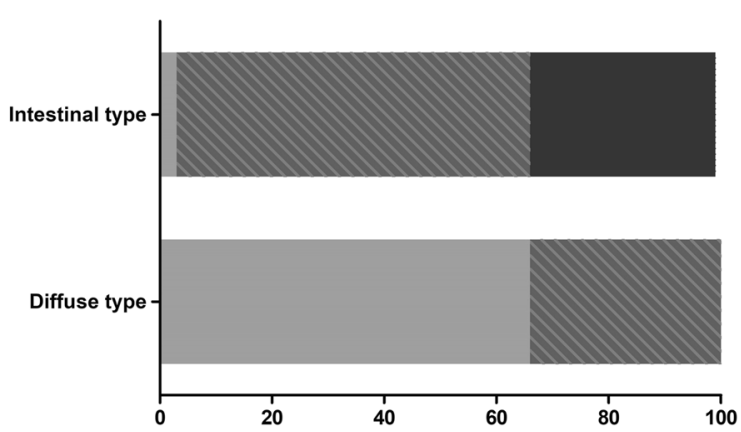

d Ovarian cancer

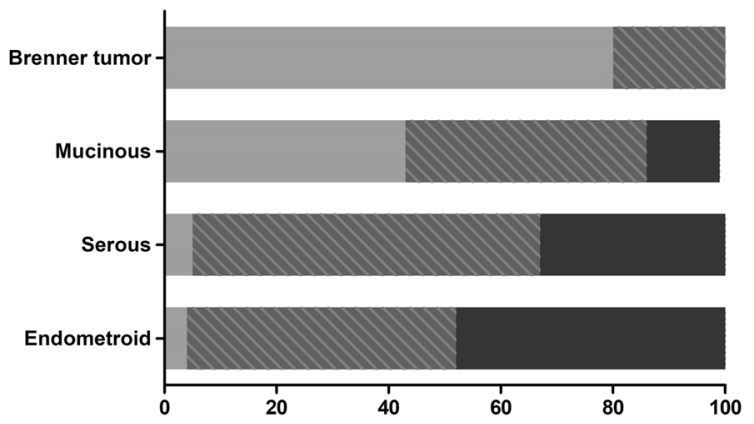

e Esophageal cancer

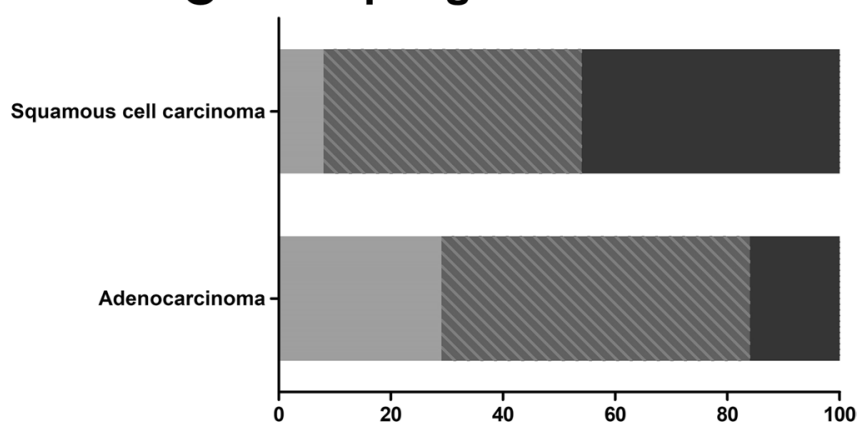

f Cervical cancer

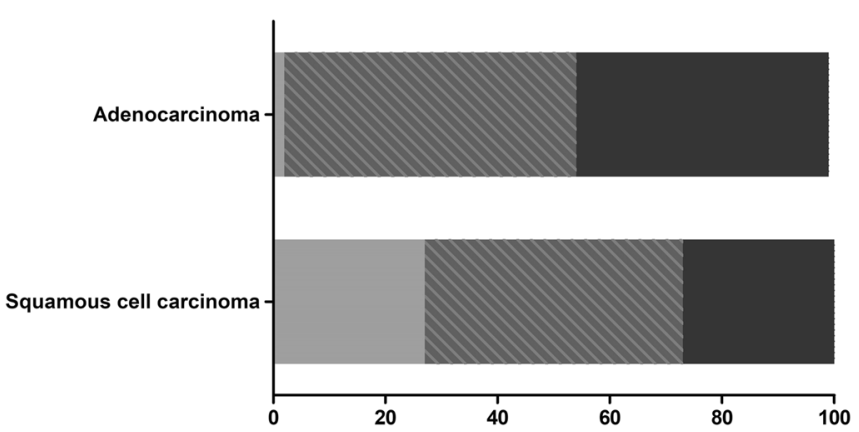

Low

High

Fig. 3 Differential expression of YKL-40 protein in selected tumor types and subtypes on multi-tumor TMA. a Thyroid cancer subtypes, $\mathbf{b}$ colorectal cancer, $\mathbf{c}$ gastric cancer, $\mathbf{d}$ ovarian cancer, $\mathbf{e}$ esophageal cancer and $\mathbf{f}$ cervical cancer

49 cell line/xenograft pairs, YKL-40 expression increased under in vivo conditions (Supplementary Fig. S4).

As the increased YKL-40 expression in vivo may result from interactions of cancer cells with their surrounding extracellular matrices, we searched the NCBI GEO database for expression data comparing cells mono-cultured and co-cultured with stromal cells. Only a limited number of experiments with YKL-40 expression data was available (GSE115052, GSE60035, GSE98154, GSE109577) [41-44]. A clear tendency of increased YKL-40 expression in co-culture could be observed in prostate and ovarian cancer cells (Supplementary Fig. S3). 


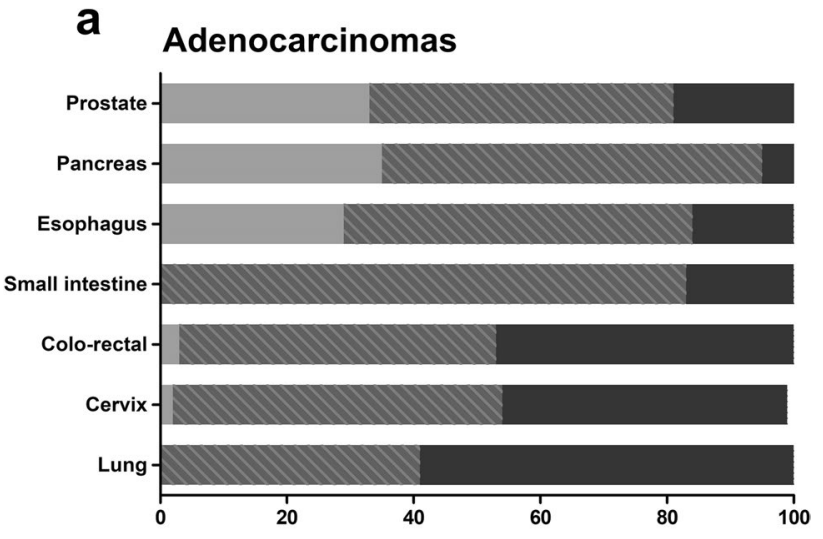

b

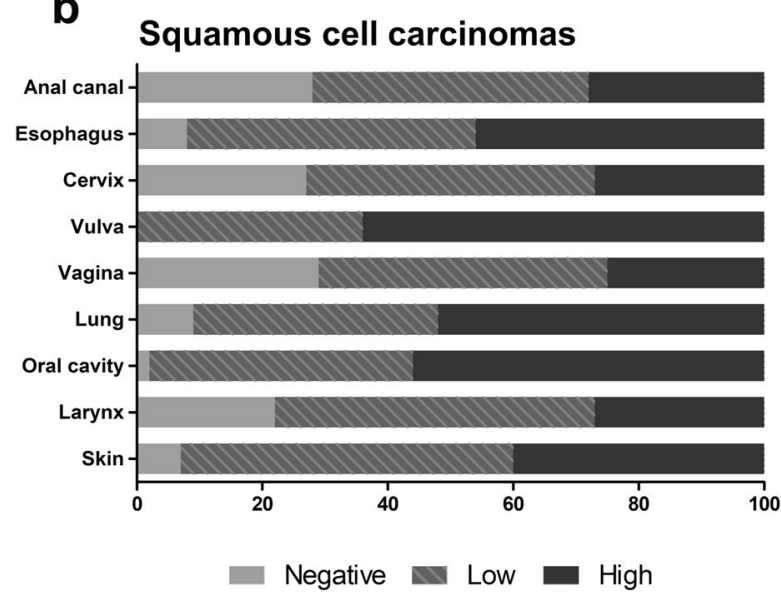

Fig. 4 Percentage of YKL-40 positive tumor samples of all tumor samples in a adenocarcinomas and $\mathbf{b}$ squamous cell carcinomas on multi-tumor TMA

\section{Discussion}

Elevated YKL-40 serum levels have been described in a growing number of inflammatory and malignant diseases and for many of them, YKL-40 has been proposed as a prognostic biomarker [45]. The biological role and function of YKL-40 in malignant progression, however, remains elusive for multiple reasons. First, cellular receptors for YKL-40 have not yet been identified. Secondly, there is opposing data for the role of YKL-40 on proliferation and tumor growth in xenograft models [22, 23]. Thirdly, the question of whether serum YKL-40 in tumor patients is derived from production and release by the tumor cells themselves or from immune and/or stromal cells due to the tumor's immunologic reaction is a matter of debate [10].

This work complements a former immunohistochemical study on YKL-40 protein expression in normal adult human tissues by Ringsholt et al. [46]. The authors found YKL-40 to be an omnipresent protein throughout the normal tissues analyzed, but the number of samples was relatively small. Protein expression data in tumor tissues, however,
Table 2 Immunohistochemical scoring of YKL-40 expression in xenografts of human cancer cell lines Staining intensity was assessed on a scale from ' - ' $=$ negative over ' + ' $=$ weak to ' ++ ' $=$ high expression

\begin{tabular}{|c|c|c|c|}
\hline Cell Line & Score & Cell Line & Score \\
\hline Melanoma & & HNSCC & \\
\hline LOX-IMVI & + & UT-SCC-2 & - \\
\hline FEMX-I & ++ & UT-SCC-16A & + \\
\hline MV3 & - & UT-SCC-24A & - \\
\hline MeWo & + & UT-SCC-24B & ++ \\
\hline MDA-MB-435 & + & $\begin{array}{l}\text { UT-SCC-60A } \\
\text { Carey } 24\end{array}$ & + \\
\hline \multicolumn{4}{|l|}{ Pancreatic Cancer } \\
\hline PANC-1 & ++ & Neuroblastoma & \\
\hline PaCa 5061 & + & KELLY & + \\
\hline PaCa 5072 & - & IMR-32 & - \\
\hline \multirow[t]{2}{*}{ BxPC-3 } & ++ & LA-N-1 & - \\
\hline & & LA-N-5 & - \\
\hline Colorectal Cancer & & SK-N-SH & + \\
\hline HT-29 & + & LS & - \\
\hline SW480 & + & & \\
\hline $\mathrm{CaCo}$ & ++ & Prostate & \\
\hline \multirow[t]{2}{*}{ HCT 116} & + & PC3 & + \\
\hline & & C5 & + \\
\hline SCLC & & DU-145 & - \\
\hline H69AR1 & - & $\mathrm{LNCaP}$ & - \\
\hline H69AR3 & - & & \\
\hline NCI-H82 & - & Osteosarcoma & \\
\hline \multirow[t]{2}{*}{ SW2 } & - & U2OS & + \\
\hline & & HOS & - \\
\hline \multicolumn{4}{|l|}{ Breast Cancer } \\
\hline DU4475 & - & Ovarian Cancer & \\
\hline MCF-7 & + & OVCAR & + \\
\hline MDA-MB-231 & + & SKOV3 & ++ \\
\hline $\mathrm{T}-47 \mathrm{D}$ & - & & \\
\hline
\end{tabular}

are only available for some selected entities and subtypes. So far, integrative analyses of YKL-40 expression in cancer, whether in primary human tumor tissues or human cancer cell lines, are only available on the mRNA level. The lack of actual protein expression data is critical for the interpretation of the functional role of YKL-40 in tissues. In a comprehensive analysis of YKL-40 expression in differentiating mesenchymal stem cells (MSCs), Hoover et al. found undifferentiated MSCs to transcribe significant levels of YKL-40 mRNA, whereas YKL-40 protein was absent both in cell lysates and media supernatants [47]. Moreover, they found that YKL-40 mRNA was not immediately translated into protein, but with a delay of at least $24 \mathrm{~h}$ following the addition of osteoblast or chondrocyte differentiation media. The authors hypothesized that YKL-40 may be regulated by (one or more) microRNAs (miRNAs) binding to YKL-40 mRNA. 

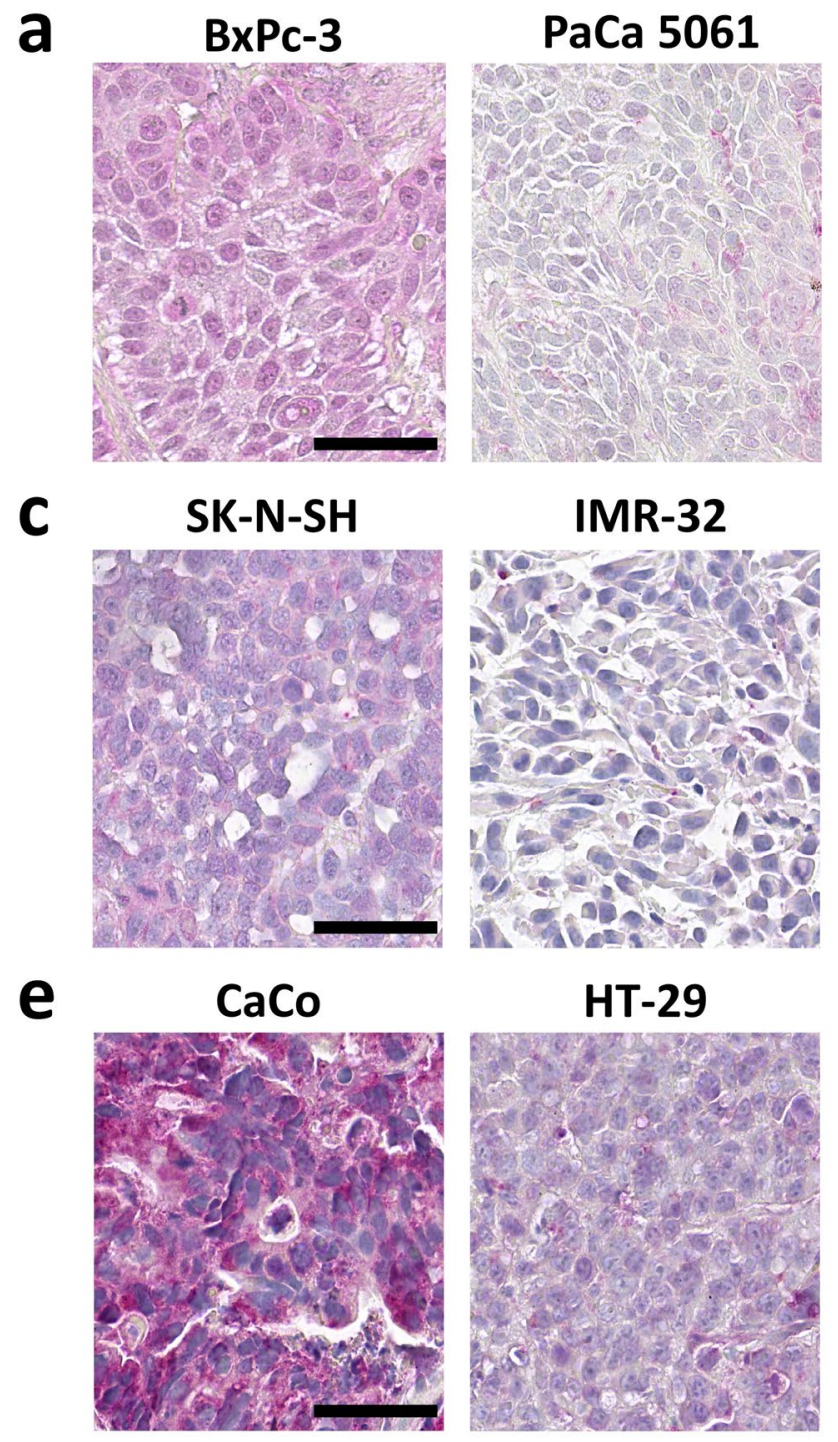

Fig. 5 Representative YKL-40 immunostaining results in mouse xenograft tumors derived from different human cancer cell lines. Cancer cells were identified morphologically, and YKL-40 staining was assessed in areas of vital tumor tissue. a Pancreatic cancer cell lines,

This hypothesis was at least partly supported by association studies of miRNAs and mesenchymal markers (among them YKL-40) in glioblastoma [48], but needs further verification. These findings imply that mRNA quantification alone may not reflect the complex regulation of YKL-40 in cancer progression and provides a rationale for studying YKL-40 expression at the protein level.

In accordance with immunohistochemical data on normal tissues [46], it is not surprising that YKL-40 protein could be detected in a high number of tumors from all entities in our study. On the other hand, in a significant proportion of tumors YKL-40 expression was specifically absent, whereas in many tumors the staining frequency and
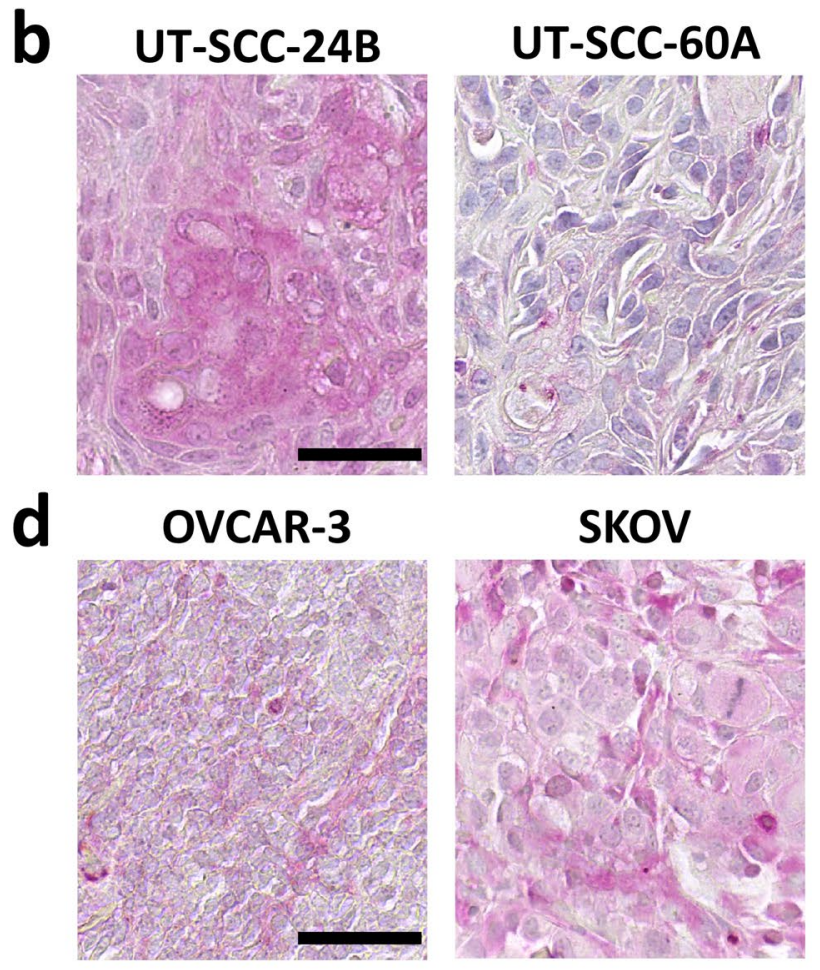

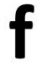

\section{FEMX-I}
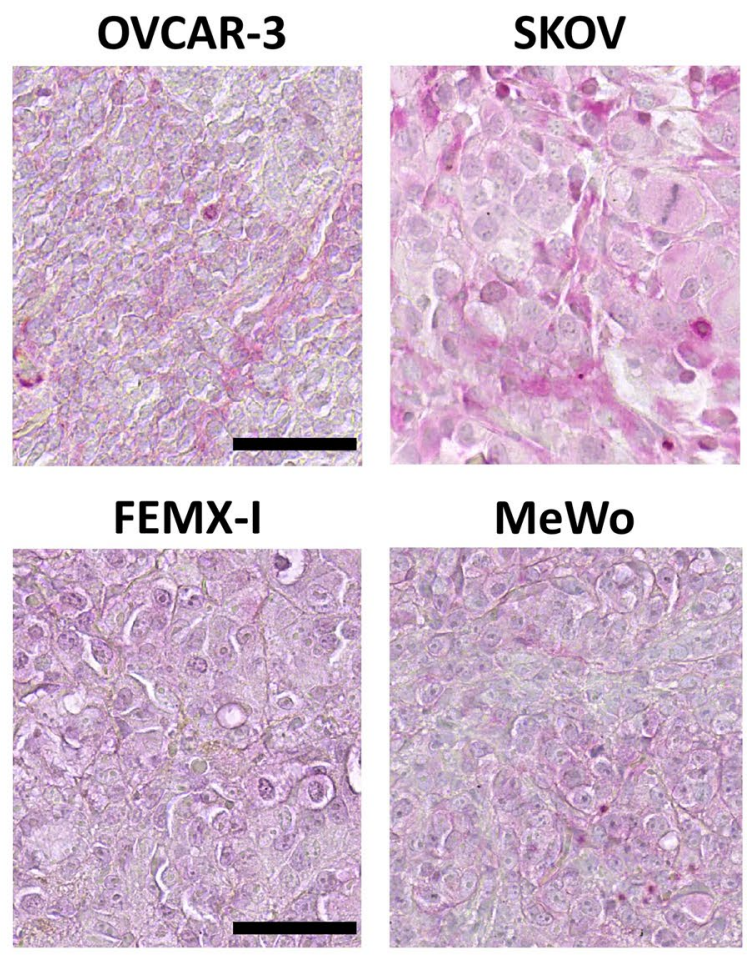

b head and neck squamous cell cancer cell lines, $\mathbf{c}$ neuroblastoma cell lines, $\mathbf{d}$ ovarian cancer cell lines, $\mathbf{e}$ colorectal cancer cell lines, $\mathbf{f}$ melanoma cell lines. Scale bars $=50 \mu \mathrm{m}$

intensity of stroma cells surpassed those of the tumor cells. We detected intensely stained stroma cells that were surrounded by finely granular material. Morphologically, these cells most likely represent infiltrating neutrophilic granulocytes. While Ringsholt et al. found that this observation was exceptionally made in surrounding tissues of the appendix [46], we found that this observation was true for most of the tumors. To what extent YKL-40 serum levels are fueled by release from the tumor cells themselves or from specific granules of the neutrophilic granulocytes [4] needs to be addressed in future studies. Further, YKL-40 expression in serum, tumor tissue and adjacent stroma should be studied coherently to answer the question of whether those patients 
Fig. 6 Representative YKL40 immunostaining results of adjacent stroma in mouse xenograft tumor tissues (a-c) and human tumor samples (d-f). Extracellular matrix components and stroma cells were identified morphologically. a Head and neck squamous cell cancer cell line UT-SCC-16A, b melanoma cell line FEMX-1, c pancreatic cancer cell line BxPC-3, $\mathbf{d}$ breast cancer, phyllodes subtype, e squamous cell esophageal cancer, $\mathbf{f}$ squamous cell lung cancer. Arrowheads point to fine granular staining in extracellular matrix components (mouse xenograft tumor tissue, a-c) or small nucleated cells residing in adjacent tumor stroma and surrounded by fine granular staining (human tumor samples, $\mathbf{d}-\mathbf{f}$ ). Scale bars $=50 \mu \mathrm{m}$
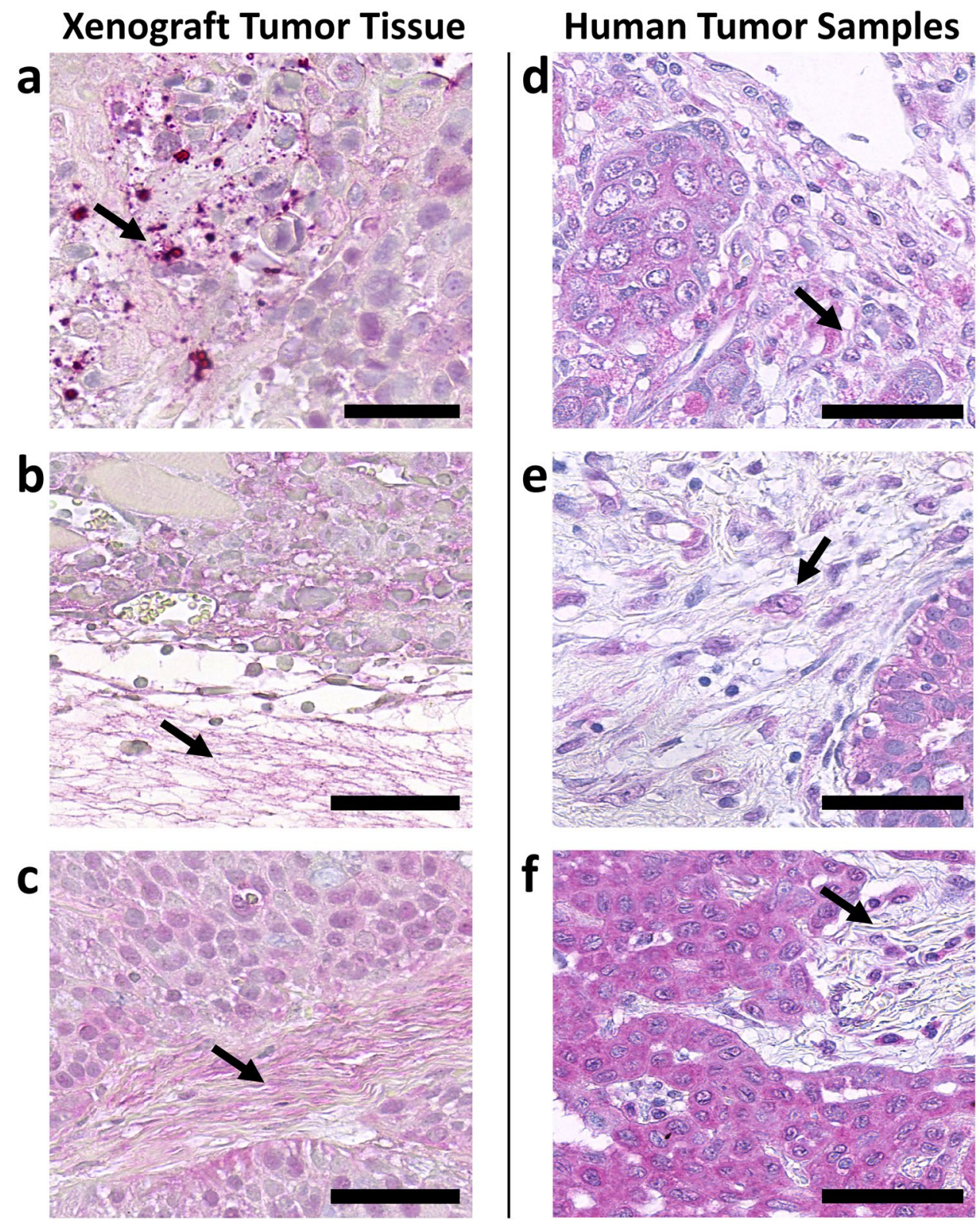

with no YKL-40 expression in the tumor tissues still have elevated serum levels.

The herein used antibody Mab 201.F9 has been validated for immunohistochemistry purposes by others in the past and was demonstrated to have specific, strong labeling properties with a lack of nonspecific background staining [21, 49]. Moreover, we found that Mab 201.F9 showed no crossreactivity with murine YKL-40. This notion is of specific importance when interpreting our results in mouse xenograft tumor tissues derived from human cancer cell lines. Our results clearly suggest that human cancer cell lines, when exposed to in vivo conditions, upregulate YKL-40 expression and secrete YKL-40 into the surrounding mousederived stroma. It is known that three-dimensional cell-tocell contact and cell-to-matrix contact may influence a cell's gene expression pattern. Our findings were further corroborated by in silico analysis of YKL-40 mRNA expression profiles in murine tumor xenograft tissues compared with its expression in the parental cell line taken from 2-D culture.

In a glioblastoma xenograft model, Francescone et al. showed that YKL-40 binds to heparan sulfate of the ectodomains of syndecan-1 and initiates coupling with integrin $\alpha_{\mathrm{v}} \beta_{3}$ [17]. In endothelial cells this action was followed by activation of a signaling cascade engaging focal adhesion kinase (FAK) and the mitogen-activated protein kinase/ extracellular signal-regulated kinase (MAPK/ERK) pathway leading to elevated levels of vascular endothelial growth factor (VEGF) and enhanced angiogenesis [17, 18, 22]. Syndecans act as matrix co-receptors with integrins, thereby mediating cell-cell and cell-matrix adhesion and promoting 
proliferation, differentiation and migration [50]. Upregulation of YKL-40 in vivo may be one essential component in the binding and activation of these receptors. In many of the cell lines tested in our study, YKL-40 mRNA expression increased markedly in vivo in the xenograft tumor tissues. These results may have implications for research on the role of YKL-40 in tumor models.

In the past, much of the work on the effect of YKL-40 on malignant progression in tumor models has been based on glioblastoma cells. This restriction is most probably due to the fact that only a few cell lines produce YKL-40 protein in vitro and in vivo such as the glioblastoma cell lines U87, U1242MG, U343MG and U1231MG, and the osteosarcoma cell line MG63 [51]. As in vitro analyses revealed lack of endogenous YKL-40 expression in other cancer cell lines, this notion provided reason to use them as the null background against which biological activities of YKL-40 have been examined, among them MDA-MB-231 and HCT-116 cells engineered to ectopically express YKL-40 [18]. Our results suggest that this ectopic overexpression of YKL-40 may override the pathways that physiologically (up-)regulate its expression in vivo. Therefore, careful consideration should be taken when choosing a tumor model. Our study may pave the way for examining the effects of YKL-40 in tumor models of other entities as well.

In conclusion, our data provide new insight into YKL40 expression at the protein level in various tumor entities and its regulation in tumor models. Our results may provide a rationale for characterizing YKL-40 as a feasible distinguishing tissue marker in tumor subtypes. Our data also suggest that YKL-40 expression is a common feature of tumor progression in vivo, while the absence of YKL-40 expression in vitro may be an artifact of cell culture.

Supplementary Information The online version contains supplementary material available at https://doi.org/10.1007/s13402-021-00630-z.

Acknowledgements We sincerely thank Prof. Paul Price, UC San Diego, USA for kindly providing the antibody as well as Prof. Dr. Guido Sauter and Prof. Dr. Ronald Simon, Institute of Pathology, University Medical Center Hamburg-Eppendorf, Germany for providing human tumor samples. We also thank T. Gosau, A. Kerbs, C. Knies, M. Märker and J. Schröder-Schwarz for excellent technical assistance.

Authors' contributions: Conceived and designed the experiments: LCB, US. Performed the experiments: TF, SC. Analyzed the data: LCB. Wrote the paper: LCB. Revised the manuscript: US.

Funding Open Access funding enabled and organized by Projekt DEAL.

Data availability All data are available in the manuscript.

\section{Declarations}

Conflict of interest The authors declare that they have no conflicting or competing interests.
Ethics approval The use of archived diagnostic left-over tissues for the manufacturing of TMAs and their analysis for research purposes has been approved by local laws (HmbKHG, $\$ 12,1)$ and by the local ethics committee (Ethics commission Hamburg, WF-049/09). All work has been carried out in compliance with the Helsinki Declaration.

Consent to participate Written, informed consent was obtained from all participants.

Consent for publication Written, informed consent to participate also included consent for publication.

Open Access This article is licensed under a Creative Commons Attribution 4.0 International License, which permits use, sharing, adaptation, distribution and reproduction in any medium or format, as long as you give appropriate credit to the original author(s) and the source, provide a link to the Creative Commons licence, and indicate if changes were made. The images or other third party material in this article are included in the article's Creative Commons licence, unless indicated otherwise in a credit line to the material. If material is not included in the article's Creative Commons licence and your intended use is not permitted by statutory regulation or exceeds the permitted use, you will need to obtain permission directly from the copyright holder. To view a copy of this licence, visit http://creativecommons.org/licenses/by/4.0/.

\section{References}

1. G.H. Renkema, R.G. Boot, F.L. Au, W.E. Donker-Koopman, A. Strijland, A.O. Muijsers, M. Hrebicek, J.M.F.G. Aerts, Chitotriosidase, a chitinase, and the $39-\mathrm{kDa}$ human cartilage glycoprotein, a chitin-binding lectin, are homologues of family 18 glycosyl hydrolases secreted by human macrophages. Eur. J. Biochem. 251, 504-509 (1998)

2. B.E. Hakala, C. White, A.D. Recklies, Human cartilage gp-39, a major secretory product of articular chondrocytes and synovial cells, is a mammalian member of a chitinase protein family. J. Biol. Chem. 268, 25803-25810 (1993)

3. C.G. Lee, D. Hartl, G.R. Lee, B. Koller, H. Matsuura, C.A. Da Silva, M.H. Sohn, L. Cohn, R.J. Homer, A.A. Kozhich, A. Humbles, J. Kearley, A. Coyle, G. Chupp, J. Reed, R.A. Flavell, J.A. Elias, Role of breast regression protein 39 (BRP-39)/chitinase 3-like-1 in Th2 and IL-13-induced tissue responses and apoptosis. J. Exp. Med. 206, 1149-1166 (2009)

4. B. Volck, P.A. Price, J.S. Johansen, O. Sørensen, T.L. Benfield, H.J. Nielsen, J. Calafat, N. Borregaard, YKL-40, a mammalian member of the chitinase family, is a matrix protein of specific granules in human neutrophils. Proc. Assoc. Am. Physicians 110, 351-360 (1998)

5. T. Suzuki, S. Hashimoto, N. Toyoda, S. Nagai, N. Yamazaki, H.Y. Dong, J. Sakai, T. Yamashita, T. Nukiwa, K. Matsushima, Comprehensive gene expression profile of LPS-stimulated human monocytes by SAGE. Blood 96, 2584-2591 (2000)

6. J.S. Johansen, T. Olee, P.A. Price, S. Hashimoto, R.L. Ochs, M. Lotz, Regulation of YKL-40 production by human articular chondrocytes. Arthritis Rheum. 44, 826-837 (2001)

7. M. Rehli, H.-H. Niller, C. Ammon, S. Langmann, L. Schwarzfischer, R. Andreesen, S.W. Krause, Transcriptional regulation of CHI3L1, a marker gene for late stages of macrophage differentiation. J. Biol. Chem. 278, 44058-44067 (2003)

8. K. Dasuri, M. Antonovici, K. Chen, K. Wong, K. Standing, W. Ens, H. El-Gabalawy, J.A. Wilkins, The synovial proteome: 
analysis of fibroblast-like synoviocytes. Arthritis Res. Ther. 6, R161 (2004)

9. J. Kastrup, Can YKL-40 be a new inflammatory biomarker in cardiovascular disease? Immunobiology 217, 483-491 (2012)

10. S. Libreros, V. Iragavarapu-Charyulu, YKL-40/CHI3L1 drives inflammation on the road of tumor progression. J. Leukoc. Biol. 98, 931-936 (2015)

11. C. Cintin, J.S. Johansen, I.J. Christensen, P.A. Price, S. Sørensen, H.J. Nielsen, Serum YKL-40 and colorectal cancer. Br. J. Cancer 79, 1494 (1999)

12. B. Bian, L. Li, J. Yang, Y. Liu, G. Xie, Y. Zheng, L. Zeng, J. Zeng, L. Shen, Prognostic value of YKL-40 in solid tumors: a metaanalysis of 41 cohort studies. Cancer Cell Int. 19, 259 (2019)

13. A.D. Recklies, C. White, H. Ling, The chitinase 3-like protein human cartilage glycoprotein 39 (HC-gp39) stimulates proliferation of human connective-tissue cells and activates both extracellular signal-regulated kinase- and protein kinase B-mediated signalling pathways. Biochem. J. 365, 119-126 (2002)

14. K.M. Malinda, L. Ponce, H.K. Kleinman, L.M. Shackelton, A.J.T. Millis, Gp38k, a protein synthesized by vascular smooth muscle cells, stimulates directional migration of human umbilical vein endothelial cells. Exp. Cell Res. 250, 168-173 (1999)

15. K.C. Nishikawa, A.J.T. Millis, gp38k (CHI3L1) is a novel adhesion and migration factor for vascular cells. Exp. Cell Res. 287, 79-87 (2003)

16. A. Saidi, S. Javerzat, A. Bellahcène, J.D. Vos, L. Bello, V. Castronovo, M. Deprez, H. Loiseau, A. Bikfalvi, M. Hagedorn, Experimental anti-angiogenesis causes upregulation of genes associated with poor survival in glioblastoma. Int. J. Cancer 122, 2187-2198 (2008)

17. R.A. Francescone, S. Scully, M. Faibish, S.L. Taylor, D. Oh, L. Moral, W. Yan, B. Bentley, R. Shao, Role of YKL-40 in the angiogenesis, radioresistance, and progression of glioblastoma. J. Biol. Chem. 286, 15332-15343 (2011)

18. R. Shao, K. Hamel, L. Petersen, Q.J. Cao, R.B. Arenas, C. Bigelow, B. Bentley, W. Yan, YKL-40, a secreted glycoprotein, promotes tumor angiogenesis. Oncogene 28, 4456-4468 (2009)

19. N. Ngernyuang, W. Yan, L.M. Schwartz, D. Oh, Y. Liu, H. Chen, R. Shao, A heparin binding motif rich in arginine and lysine is the functional domain of YKL-40. Neoplasia 20, 182-192 (2018)

20. F. De Ceuninck, S. Gaufillier, A. Bonnaud, M. Sabatini, C. Lesur, P. Pastoureau, YKL-40 (Cartilage gp-39) induces proliferative events in cultured chondrocytes and synoviocytes and increases glycosaminoglycan synthesis in chondrocytes. Biochem. Biophys. Res. Commun. 285, 926-931 (2001)

21. J.S. Johansen, P.E. Høyer, L.A. Larsen, P.A. Price, K. Møllgård, YKL-40 protein expression in the early developing human musculoskeletal system. J. Histochem. Cytochem. 55, 1213-1228 (2007)

22. M. Faibish, R. Francescone, B. Bentley, W. Yan, R. Shao, A YKL40-Neutralizing antibody blocks tumor angiogenesis and progression: a potential therapeutic agent in cancers. Mol. Cancer Ther. 10, 742-751 (2011)

23. J. Salamon, T. Hoffmann, E. Elies, K. Peldschus, J.S. Johansen, G. Lüers, U. Schumacher, D. Wicklein, Antibody directed against human YKL-40 increases tumor volume in a human melanoma xenograft model in scid mice. PLOS One 9, e95822 (2014)

24. S. Sodeur, S. Ullrich, H. Gustke, U. Zangemeister-Wittke, U. Schumacher, Increased numbers of spontaneous SCLC metastasis in absence of NK cells after subcutaneous inoculation of different SCLC cell lines into pfp/rag2 double knock out mice. Cancer Lett. 282, 146-151 (2009)

25. U. Schumacher, E. Adam, Lectin histochemical HPA-binding pattern of human breast and colon cancers is associated with metastases formation in severe combined immunodeficient mice. Histochem. J. 29, 677-684 (1997)
26. J. Ghulam, C. Stuerken, D. Wicklein, R. Pries, B. Wollenberg, $\mathrm{U}$. Schumacher, Immunohistochemical analysis of transcription factors and markers of epithelial-mesenchymal transition (EMT) in human tumors. Anticancer Res. 39, 5437-5448 (2019)

27. U. Valentiner, D.M.S. Hall, S.A. Brooks, U. Schumacher, HPA binding and metastasis formation of human breast cancer cell lines transplanted into severe combined immunodeficient (scid) mice. Cancer Lett. 219, 233-242 (2005)

28. C. Schröder, U. Schumacher, V. Müller, R.M. Wirtz, T. Streichert, U. Richter, D. Wicklein, K. Milde-Langosch, The transcription factor Fra- 2 promotes mammary tumour progression by changing the adhesive properties of breast cancer cells. Eur. J. Cancer 46, 1650-1660 (2010)

29. A. Thies, S. Mauer, O. Fodstad, U. Schumacher, Clinically proven markers of metastasis predict metastatic spread of human melanoma cells engrafted in scid mice. Br. J. Cancer 96, 609-616 (2007)

30. U. Valentiner, F.-U. Valentiner, U. Schumacher, Expression of CD44 Is associated with a metastatic pattern of human neuroblastoma cells in a SCID mouse xenograft model. Tumor Biol. 29, 152-160 (2008)

31. F. Gebauer, D. Wicklein, K. Stübke, N. Nehmann, A. Schmidt, J. Salamon, K. Peldschus, M.F. Nentwich, G. Adam, G. Tolstonog, M. Bockhorn, J.R. Izbicki, C. Wagener, U. Schumacher, Selectin binding is essential for peritoneal carcinomatosis in a xenograft model of human pancreatic adenocarcinoma in pfp--/rag2-mice. Gut 62, 741-750 (2013)

32. T. Lange, S. Ullrich, I. Müller, M.F. Nentwich, K. Stübke, S. Feldhaus, C. Knies, O.J.C. Hellwinkel, R.L. Vessella, C. Abramjuk, M. Anders, J. Schröder-Schwarz, T. Schlomm, H. Huland, G. Sauter, U. Schumacher, Human prostate cancer in a clinically relevant xenograft mouse model: identification of $\beta(1,6)$-branched oligosaccharides as a marker of tumor progression. Clin. Cancer Res. 18, 1364-1373 (2012)

33. T. Lange, S.J. Oh-Hohenhorst, S.A. Joosse, K. Pantel, O. Hahn, T. Gosau, S.A. Dyshlovoy, J. Wellbrock, S. Feldhaus, H. Maar, R. Gehrcke, M. Kluth, R. Simon, T. Schlomm, H. Huland, U. Schumacher, Development and characterization of a spontaneously metastatic patient-derived xenograft model of human prostate cancer. Sci. Rep. 8, 17535 (2018)

34. U. Valentiner, J. Knips, R. Pries, T. Clauditz, A. Münscher, G. Sauter, B. Wollenberg, U. Schumacher, Selectin binding sites are involved in cell adhesive properties of head and neck squamous cell carcinoma. Cancers 11, 1672 (2019)

35. L. Böckelmann, C. Starzonek, A.-C. Niehoff, U. Karst, J. Thomale, H. Schlüter, C. Bokemeyer, A. Aigner, U. Schumacher, Detection of doxorubicin, cisplatin and therapeutic antibodies in formalin-fixed paraffin-embedded human cancer cells. Histochem. Cell Biol. 153, 367-377 (2020)

36. R.J. Biggar, J.S. Johansen, K.E. Smedby, K. Rostgaard, E.T. Chang, H.-O. Adami, B. Glimelius, D. Molin, S. Hamilton-Dutoit, M. Melbye, H. Hjalgrim, Serum YKL-40 and interleukin 6 levels in Hodgkin lymphoma. Clin. Cancer Res. 14, 6974-6978 (2008)

37. S.I. Sherman, P. Angelos, D.W. Ball, D. Byrd, O.H. Clark, G.H. Daniels, R.A. Dilawari, H. Ehya, W.B. Farrar, R.F. Gagel, F. Kandeel, R.T. Kloos, P. Kopp, D.M. Lamonica, T.R. Loree, W.M. Lydiatt, J. McCaffrey, J.A. Olson, J.A. Ridge, J.P. Shah, J.C. Sisson, R.M. Tuttle, M.M. Urist, National comprehensive cancer network thyroid carcinoma panel, thyroid carcinoma. J. Natl. Compr. Cancer Netw. JNCCN 5, 568-621 (2007)

38. M. Ghandi, F.W. Huang, J. Jané-Valbuena, G.V. Kryukov, C.C. Lo, E.R. McDonald, J. Barretina, E.T. Gelfand, C.M. Bielski, H. Li, K. Hu, A.Y. Andreev-Drakhlin, J. Kim, J.M. Hess, B.J. Haas, F. Aguet, B.A. Weir, M.V. Rothberg, B.R. Paolella, M.S. Lawrence, R. Akbani, Y. Lu, H.L. Tiv, P.C. Gokhale, A. de Weck, A.A. Mansour, C. Oh, J. Shih, K. Hadi, Y. Rosen, J. Bistline, K. 
Venkatesan, A. Reddy, D. Sonkin, M. Liu, J. Lehar, J.M. Korn, D.A. Porter, M.D. Jones, J. Golji, G. Caponigro, J.E. Taylor, C.M. Dunning, A.L. Creech, A.C. Warren, J.M. McFarland, M. Zamanighomi, A. Kauffmann, N. Stransky, M. Imielinski, Y.E. Maruvka, A.D. Cherniack, A. Tsherniak, F. Vazquez, J.D. Jaffe, A.A. Lane, D.M. Weinstock, C.M. Johannessen, M.P. Morrissey, F. Stegmeier, R. Schlegel, W.C. Hahn, G. Getz, G.B. Mills, J.S. Boehm, T.R. Golub, L.A. Garraway, W.R. Sellers, Next-generation characterization of the Cancer Cell Line Encyclopedia. Nature 569, 503-508 (2019)

39. J. Barretina, G. Caponigro, N. Stransky, K. Venkatesan, A.A. Margolin, S. Kim, C.J. Wilson, J. Lehár, G.V. Kryukov, D. Sonkin, A. Reddy, M. Liu, L. Murray, M.F. Berger, J.E. Monahan, P. Morais, J. Meltzer, A. Korejwa, J. Jané-Valbuena, F.A. Mapa, J. Thibault, E. Bric-Furlong, P. Raman, A. Shipway, I.H. Engels, J. Cheng, G.K. Yu, J. Yu, P. Aspesi, M. de Silva, K. Jagtap, M.D. Jones, L. Wang, C. Hatton, E. Palescandolo, S. Gupta, S. Mahan, C. Sougnez, R.C. Onofrio, T. Liefeld, L. MacConaill, W. Winckler, M. Reich, N. Li, J.P. Mesirov, S.B. Gabriel, G. Getz, K. Ardlie, V. Chan, V.E. Myer, B.L. Weber, J. Porter, M. Warmuth, P. Finan, J.L. Harris, M. Meyerson, T.R. Golub, M.P. Morrissey, W.R. Sellers, R. Schlegel, L.A. Garraway, The cancer cell line Encyclopedia enables predictive modelling of anticancer drug sensitivity. Nature 483, 603-607 (2012)

40. M.G. Hollingshead, L.H. Stockwin, S.Y. Alcoser, D.L. Newton, B.C. Orsburn, C.A. Bonomi, S.D. Borgel, R. Divelbiss, K.M. Dougherty, E.J. Hager, S.L. Holbeck, G. Kaur, D.J. Kimmel, M.W. Kunkel, A. Millione, M.E. Mullendore, H. Stotler, J. Collins, Gene expression profiling of 49 human tumor xenografts from in vitro culture through multiple in vivo passages - strategies for data mining in support of therapeutic studies. BMC Genomics 15, 393 (2014)

41. Q. Gao, Z. Yang, S. Xu, X. Li, X. Yang, P. Jin, Y. Liu, X. Zhou, T. Zhang, C. Gong, X. Wei, D. Liu, C. Sun, G. Chen, J. Hu, L. Meng, J. Zhou, K. Sawada, R. Fruscio, T.W. Grunt, J. Wischhusen, V.M. Vargas-Hernández, B. Pothuri, R.L. Coleman, Heterotypic CAFtumor spheroids promote early peritoneal metastasis of ovarian cancer. J. Exp. Med. 216, 688-703 (2019)

42. D. Loessner, A. Rockstroh, A. Shokoohmand, B.M. Holzapfel, F. Wagner, J. Baldwin, M. Boxberg, B. Schmalfeldt, E. Lengyel, J.A. Clements, D.W. Hutmacher, A 3D tumor microenvironment regulates cell proliferation, peritoneal growth and expression patterns. Biomaterials 190-191, 63-75 (2019)

43. Y. Yang, A. Otte, R. Hass, Human mesenchymal stroma/stem cells exchange membrane proteins and alter functionality during interaction with different tumor cell lines. Stem Cells Dev. 24, 1205-1222 (2014)

44. Z. Richards, T. McCray, J. Marsili, M.L. Zenner, J.T. Manlucu, J. Garcia, A. Kajdacsy-Balla, M. Murray, C. Voisine, A.B. Murphy, S.A. Abdulkadir, G.S. Prins, L. Nonn, Prostate stroma increases the viability and maintains the branching phenotype of human prostate organoids. IScience 12, 304-317 (2019)

45. T. Zhao, Z. Su, Y. Li, X. Zhang, Q. You, Chitinase-3 like-protein-1 function and its role in diseases. Signal Transduct. Target. Ther. 5, 1-20 (2020)

46. M. Ringsholt, E.V.S. Høgdall, J.S. Johansen, P.A. Price, L.H. Christensen, YKL-40 protein expression in normal adult human tissues - an immunohistochemical study. J. Mol. Histol. 38, 33-43 (2007)

47. D.J. Hoover, V. Zhu, R. Chen, K. Briley, P. Rameshwar, S. Cohen, F.D. Coffman, Expression of the chitinase family glycoprotein YKL-40 in undifferentiated, differentiated and trans-differentiated mesenchymal stem cells. PLOS One 8, e62491 (2013)

48. X. Ma, K. Yoshimoto, Y. Guan, N. Hata, M. Mizoguchi, N. Sagata, H. Murata, D. Kuga, T. Amano, A. Nakamizo, T. Sasaki, Associations between microRNA expression and mesenchymal marker gene expression in glioblastoma. Neuro-Oncol. 14, 1153$1162(2012)$

49. A. Roslind, J.S. Johansen, N. Junker, D.L. Nielsen, H. Dzaferi, P.A. Price, E. Balslev, YKL-40 expression in benign and malignant lesions of the breast: a methodologic study. Appl. Immunohistochem. Mol. Morphol. 15, 371-381 (2007)

50. N.A. Afratis, D. Nikitovic, H.A.B. Multhaupt, A.D. Theocharis, J.R. Couchman, N.K. Karamanos, Syndecans - key regulators of cell signaling and biological functions. FEBS J. 284, 27-41 (2017)

51. N.A. Schultz, J.S. Johansen, YKL-40-a protein in the field of translational medicine: a role as a biomarker in cancer patients? Cancers 2, 1453-1491 (2010)

Publisher's note Springer Nature remains neutral with regard to jurisdictional claims in published maps and institutional affiliations. 